\title{
SONOGRAPHIC CERVICAL CANAL LENGTH AND/ \\ OR A BISHOP SCORE ASSESSMENT AS A PREDICTOR \\ FOR SUCCESSFUL INDUCTION OF LABOR
}

Mohamed Said, Omar Khalil, Amr Mansy, Mohamed Farag Department of Obstetrics and Gynecology, Alexandria University, Egypt
Mohamed Said

Mobile: 01222904708

email: dr_msmf@yahoo.com

\begin{abstract}
Objectives: To compare transvaginal sonography for cervical length measurement and digital examination for Bishop score assessment in women undergoing labor induction at term.
\end{abstract}

Patients and Methods: A prospective study involved 140 women subjected to induction of labor. Preinduction assessment of Modified Bishop score and transvaginal ultrasound measurement of cervical length was done.

Results: One hundred and forty nulliparous women had CL $<28 \mathrm{~mm}$ and modified Bishop score of $\geq 7 ; 84.8 \%$ (123/140) of them delivered vaginally and (17/140) delivered by cesarean section Analysis of the ROC curves for cervical length and Modified Bishop score indicated that both were predictors of Successful vaginal delivery (area under the curve 0.766 vs. 0.728 ; with optimal cutoffs for predicting Vaginal delivery of $\leq 18 \mathrm{~mm}$ for cervical length and Bishop score $>7$. Cervical length had superior sensitivity ( $83.74 \%$ vs. $65.4 \%)$ and marginally better positive $(95.4 \%$ vs. $94.1 \%)$ and negative $(37.5 \%$ vs. $21.8 \%$ ) predictive values.

Conclusions:Transvaginal sonography for cervical length measurement is better tolerated than digital examination for Modified Bishop score assessment.

Key Words: Bishop Score, Transvaginal Sonography, Cervical length, Induction of Labour.

\section{INTRODUCTION}

Induction of labor is a common and essential element of contemporary obstetric practice with an incidence of approximately $20 \%$ of pregnancy. ${ }^{(1)}$ Induction of labor is indicated when benefits to the mother or the fetus outweigh those of continuity the pregnancy. ${ }^{(2)}$

Induction include immediate conditions such as ruptured membranes with chorioamnionitis or severe preeclampsia, the more common indication include membrane rupture without labor, gestational hypertension, non-reassuring fetal status, post term pregnancy and various maternal conditions such as chronic hypertension and diabetes mellitus. Several studies have shown that induction compared to expectant management is associated with a substantial reduction in perinatal mortality 2-4\%, However, approximately $20 \%$ of women having induction of labor end up having a caesarean delivery. ${ }^{(3)}$ 
The traditional method of predicting whether an induced labor will result in successful vaginal delivery is based on the preinduction "favorability" of the cervix as assessed by the Bishop score. However, this assessment is subjective and several studies have shown a poor predictive value for the outcome of the induction. ${ }^{(4)}$

Some recent studies have reported that transvaginal sonography ultrasound of the cervix may provide a more sensitive prediction of successful induction, compared to the Bishop score. Hatfield and associations performed a meta-analysis of 20 trials in which cervical length was assessed by transvaginal ultrasonography (TVUS) and used to predict successful induction of labor. Because of study criteria the authors concluded that the questions were still unanswered. ${ }^{(5)}$

The most widely accepted and used is the scoring system described by Bishop in 1964. A Bishop score of 9 conveys a high likelihood for a successful induction. A Bishop score of 4 or less indicates unfavorable cervix and may be an induction for cervix ripening. ${ }^{(6)}$

The supravaginal portion of the cervix makes up about $50 \%$ of the cervical length and varies from one a woman to another. This portion of the cervix is difficult to estimate digitally. ${ }^{(7)}$

\section{PATIENTS AND METHODS}

Preinduction cervical assessment was undertaken in 140 nulliparous women who were included in this study at El-Shatby Hospital of Alexandria University. Inclusion criteria were: singleton pregnancy, live fetus in cephalic presentation, absence of labor pain, and undergoing induction of labour at 37 to 42 weeks of gestation for a variety of indications; PROM, pre-eclampsia, diabetes maternal or gravity related, prolonged pregnancy, restricted intra-uterine fetal growth, amniotic fluid problems. Exclusion criteria were: any reason for priming and/or contra-indication for induction of labour: suspicion of fetal distress at admission, previous history of uterine surgery or contra-indications for prostaglandins or vaginal delivery.

TVS done for all studied women in lithotomy position, the vaginal probe inserted under direct visualization, and after the evacuation of the urinary bladder. The amniotic fluid, presenting part, the midline sagittal plane of the cervix localized and the vaginal probe pulled back until the lightest touch provided a good image of the cervical canal with fixation of the internal cervical os in the proximal one-third of the ultrasound image.

The probe then moved slightly to get the best longitudinal axis of the cervix.

The measurement of the CL was accurate when the following criteria fulfilled

- Sagittal plane of the cervix that allows imaging the entire length of the cervical canal

- Placement of the cervical plane in the middle of the ultrasound screen as horizontal as possible

- The absence of excess pressure on the ultrasound probe, cursors placed in precise contact with the closing points of the internal and external cervical os.

TVS examinations carried out by using Mindray machine equipped with a $7.5 \mathrm{~m} \mathrm{HZ}$ by vaginal probe.

Digital vaginal examination carried out to record the modified Bishop's score by the clinical investigator blinded to the CL measured by TVS. After measurement of CL by TVS and calculation of the modified Bishop's score, induction of labor done Misoprostol (Vagiprost $\AA$ ) inserted in the posterior vaginal fornix. Misoprostol used for labor induction if the modified Bishop's score was $>7$ (favourable cervix) and TVS $\leq 28 \mathrm{~mm}$.

Vaginal examination done 4 hourly after misoprostol insertion and further tablet might be inserted if uterine contractions were inadequate (maximum six doses).

In established labor with regular uterine contractions (4-5 uterine contractions every $10 \mathrm{~min}$, each contraction lasting for 45-60 s), vaginal examination for assessment the progress of labor done every $4 \mathrm{~h}$.

Intrapartum fetal surveillance done by intrapartum fetal heart monitoring using cardiotocography. After delivery, success (defined as vaginal birth) and duration of labor induction reviewed and statistically analyzed to compare the CL measured by TVS versus modified Bishop's score for prediction of successful labor induction in nulliparous women. 


\section{Sample size and statistical analysis}

Data were fed to the computer and analyzed using IBM SPSS software package version 20.0.(Armonk, NY: IBM Corp $)^{(8)}$ Qualitative data were described using number and percent. Quantitative data were described using range (minimum and maximum), mean, standard deviation and median. Significance of the obtained results was judged at the $5 \%$ level.

\section{RESULTS}

One hundred and forty nulliparous women were studied; the mean age of studied women was 23.7 (3.37) years, and the mean gestational age was 38 (1.2) weeks' gestation. Nearly, $84.8 \%(123 / 140)$ of the studied women delivered vaginally, whereas $11.7 \%$ (17/140) delivered by caesarean section.

\section{Table-1: Demographic and clinical details}

\begin{tabular}{|l|c|}
\hline \multicolumn{1}{|c|}{ Demographic characteristics } & Results n (140) \\
\hline Median Age & $23.7(3.37)$ \\
\hline Mean Gestational Age & $38(1.2)$ weeks \\
\hline Indications for Induction & $43(30.7 \%)$ \\
\hline Post-date & $72(51.4 \%)$ \\
\hline PROM & $22(15.7 \%)$ \\
\hline PET & $3(2.1 \%)$ \\
\hline Oligohydraminous & $\begin{array}{c}\text { Median: } 9.5 \\
\text { range: } 7-12\end{array}$ \\
\hline Study parameters & Median $18 \mathrm{~mm} \mathrm{range:} 11-25 \mathrm{~mm}$ \\
\hline Modified Bishop score & $123 / 140(84.8 \%)$ \\
\hline TVS & $17 / 140(11.7 \%)$ \\
\hline Vaginal delivery & \\
\hline Caesarean section & \\
\hline
\end{tabular}

ROC curves indicated that the best cut-off of cervical length for predicting successful induction was $\leq 18 \mathrm{~mm}$ (sensitivity $83.74 \%$, specificity $70.59 \%$, positive predictive value $95.4 \%$, negative predictive value $37.5 \%$ ) and for Bishop score it was a score of $>7$ (sensitivity $65.04 \%$, specificity $70.59 \%$, positive predictive value $94.1 \%$, negative predictive value $21.8 \%$ ).

Table (2): Agreement (sensitivity, specificity) for different parameters to predict success cases (vs failed induction)

\begin{tabular}{|l|c|c|c|c|c|c|c|c|}
\hline & AUC & $\mathbf{p}$ & $\mathbf{9 5 \%}$ C.I & $\begin{array}{c}\text { Cut } \\
\text { off }\end{array}$ & Sensitivity & Specificity & PPV & NPV \\
\hline $\begin{array}{l}\text { Total bishop } \\
\text { score }\end{array}$ & $\mathbf{0 . 7 2 8 *}$ & $<0.001 *$ & $\begin{array}{c}0.628- \\
0.828\end{array}$ & $>7$ & 65.04 & 70.59 & 94.1 & 21.8 \\
\hline $\begin{array}{l}\text { Cervical length } \\
(\mathbf{m m})\end{array}$ & $\mathbf{0 . 7 6 6 *}$ & $<0.001 *$ & $0.615-0.917$ & $\leq 18$ & 83.74 & 70.59 & 95.4 & 37.5 \\
\hline
\end{tabular}




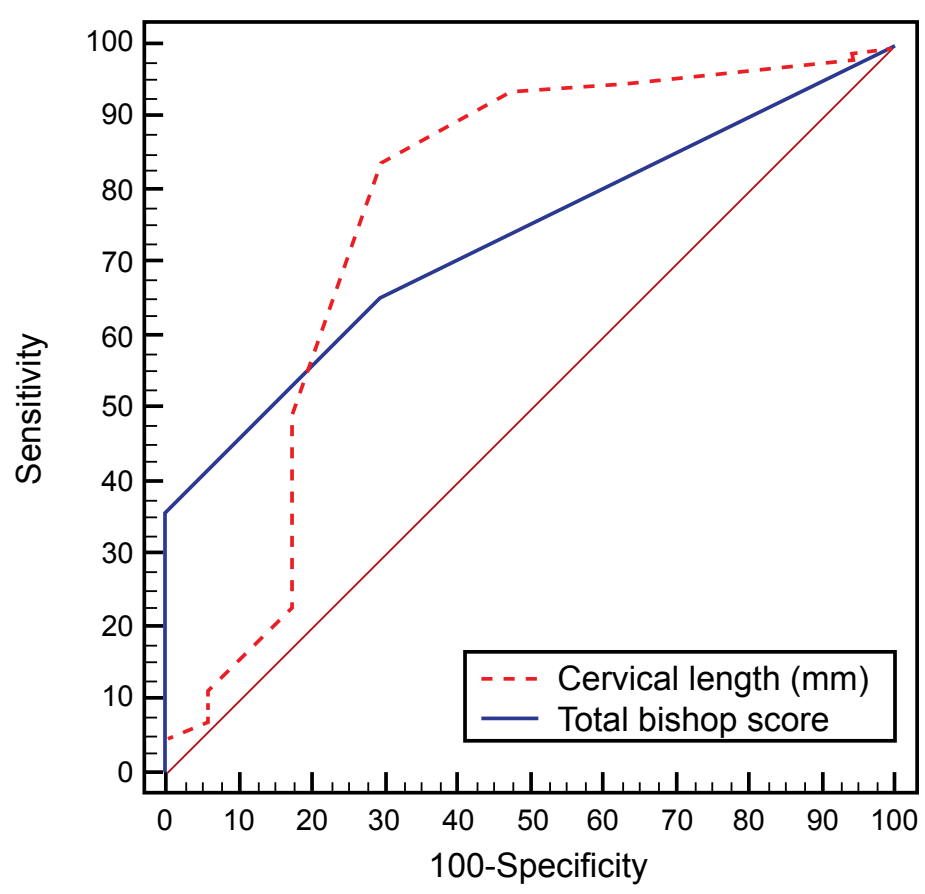

Figure (1): ROC curve for different parameters to predict successcases (vs failed induction)

The AUCs indicated that both cervical length and Bishop score were useful predictors of Cesarean delivery in labor induction (Figure 1). AUC, sensitivity, positive and negative predictive values as well as accuracy were marginally better with transvaginal sonography than bishop score in predicting success of induction.

\section{DISCUSSION}

Labor induction is one of the most common interventions in obstetric practice. Assessment of cervix has been used as a prediction of the successful vaginal delivery. Labor induction with a low cervical score has been associated with failure of induction, prolonged labor and a high rate of caesarean deliveries. Traditionally, the Bishop's Score has been used to assess the cervix. ${ }^{(9)}$

So, this study was designed to investigate transvaginal Ultrasonographic cervical measurement as a predictor of duration of labor and successful induction resulting in vaginal delivery and also compare the performance of ultrasonographic cervical measurement with that of the Modified Bishop's Score in predicting the outcome of labor induction.

In this study, cervical assessment by transvaginal ultrasonography, particularly the measurement of cervical length, showed a significant predictability for successful labor induction.
However, digital examination has limitations on objectivity and reliability. In addition, the predictive value of the Bishop's Score for successful labor induction has been reported to be poor, especially in cases with low scores.

Digital examination has limitation in assessing the change of the internal os when the external os is closed. The ability of ultrasonography to visualize the internal os can help differentiate the patients with different outcomes in labor induction.

Bishop Score is subjective scoring system; investigators tried to find another way to objectively. Predict the success of labor induction. Ware and Raynor, suggested that cervical shortening by TVUS is equal to cervical effacement detected during vaginal examination. ${ }^{(10)}$

The results of our study agree with the results done by El-Mekkawi et al 2017 that showed cervical canal length by TVUS was significantly more specific with more PPV compared to Bishop score in prediction of successful induction of labor. ${ }^{(11)}$

Whereas El-Mekkawi et al 2017 studied Two hundred and ten nulliparous women; the mean age of studied women was 24.13 years, and the mean gestational age was 38 weeks' gestation.

Receiver operator characteristics curve analysis showed that CL $<28 \mathrm{~mm}$ had $87.5 \%$ sensitivity, $86.25 \%$ specificity, $61.4 \%$ positive predictive value (PPV), and $96.5 \%$ negative predictive value (NPV) for successful labor induction, whereas modified Bishop's score $>4$ had $62.5 \%$ sensitivity, $50 \%$ specificity, $23 \%$ PPV, and $84.2 \%$ NPV for prediction of successful labor induction.

While in our study, one hundred and forty nulliparous women were studied; the mean age was 23.7 years, and the mean gestational age was 38.7 week's gestation. ROC curve analysis showed that CL $\leq 18 \mathrm{~mm}$ had $83.74 \%$ sensitivity, $70.59 \%$ specifity, 95.4\% PPV, and 37.5\% NPV for successful labor induction, whereas modified bishop's score $>7$ had $65.04 \%$ sensitivity, $70.59 \%$ specificity, $94.1 \% \mathrm{PPV}$, and $21.8 \% \mathrm{NPV}$ for prediction of successful labor induction.

Kanwar SN et al 2015, showed that the measurement of cervical length by transvaginal ultrasonography provides a better prediction of the likelihood of vaginal delivery within $24 \mathrm{hrs}$ of induction. The 
study was conducted in the Department of Obstetrics and Gynaecology, SMS Medical College, Jaipur on 110 nulliparous women under 35 years old at term. ${ }^{(12)}$

On statistical analysis found that ultrasonographic CL was better predictor of successful labor induction than clinical evaluation of cervix by Bishop's Score with cut off value of Bishop's Score being $>6$ and of cervical length being $<3.5 \mathrm{~cm}$.

Sensitivity and specificity of cervical length being $57.35 \%$ and $100 \%$ respectively and Sensitivity and specificity of Bishop's Score being 34.43\% and $93.88 \%$ respectively $55.74 \%$ and $100 \%$ respectively. In comparison with current study our results was more specific and sensitive because of the cut off value of CL $\leq 28 \mathrm{~mm}$ and bishop's score $>7$ while their cut off value of $\mathrm{CL}<35 \mathrm{~mm}$ and bishop's score $>6$.

The result of present study correlates with Panchampreet Kaur et al 2017 who designed a prospective double blinded observational study which included patients undergoing delivery following induction of labour with pharmacological methods in the labour ward at a tertiary care centre in South India for a period of one year. this study conducted on 117 nulliparous women with mean age 25.6 years old and mean gestational age at time of induction was 39.33 week. ${ }^{(13)}$

In the receiver operating characteristic (ROC) curves showed that the best cut-off point for the prediction of successful induction was 3 for the Bishop score with a sensitivity of $69 \%$ and a specificity of $75 \%$ and that for cervical length was 28 $\mathrm{mm}$ with a sensitivity of $73 \%$ and a specificity of $81 \%$; which almost resemble the results of our study.

Our result also correlates with Bastani el al 2011 who designed a prospective study on 2oo nullipa- rous women at at Alzahra University Hospital in Tabriz, northwest Iran ; the study showed that cervical length measured by transvaginal ultrasonography has the potential to replace the traditional Bishop score, provided that such a facility is available when needed. ${ }^{(14)}$

The results of current study disagree with Khandelwal et al 2017 study which concluded in The Bishop score was superior in predicting the response to induction as compared to the cervical length measured by transvaginal ultrasonography; whereas the study designed only in 66 nulliparous women and defined the successful induction of labor as achievement of vaginal delivery in 12 hours rather than 24 hours in current study.

A Cochrane review did not demonstrate superiority of one method over the other in terms of the main outcomes assessed. While use of TVUS was associated with anincreased need for misoprostol for cervical ripening, both methods could be complementary. ${ }^{(15)}$

Halil et al, Ware et al, Anish et al and Daskalakis et al ${ }^{(16)}$ studies showed that cervical length and Bishop score combined with cervical length having better predictability $(\mathrm{P}<0.001)$ than Bishop score alone, while our study showed that the superiority of TVUS of cervical canal length on Bishop score.

\section{CONCLUSION}

The current study suggests that the measurement of cervical length by transvaginal ultrasonography provides a better prediction of the likelihood of vaginal delivery within $24 \mathrm{hrs}$ of induction. In addition, ultrasonographic cervical assessment has been known as a reproducible, objective and quantitative method and can be performed easily in the setting where the appropriate equipment and expertise are available. 


\section{REFERENCES}

1. Zhang J, Yancey MK, Henderson CE.US national trends in labor induction. J Reprod Med 2002;47:120-4

2. Anish K, Vanita S, Rashmi B. Pre-induction sonographic assessment of the cervix in the prediction of successful induction of labor in nulliparous women. Australian and New Zealand Journal of Obstetrics and Gynecology 2007;47:389-93.

3. Arulkumaran S, Gibb DMF, Tambyraja RL, Heng SH, Ratnam SS. Induction of labour. Aust NZ J ObstetGynaecol1985;25:190-3.

4. Friedman EA, Niswander KR, Bayonet-Rivera NP, Sachtleben MR. Sachtleben MR Relation of prelabour evaluation to inducibility and the course of labour. Obstet Gynecol1966; 28:495-501.

5. Selhi M, Surapaneni T. Pre induction sonographic measurement of cervical length: An adjunct to Bishop Score? Fernandez Hospital Journal of perinatalogy 2010; 1.

6. Bishop EH. Pelvic scoring for elective induction. Obstet Gynecol 1964; 24:266-68.

7. Bouyer J, Papiernik E, Dreyfus J, Collins D, Wninisdoerffer B, Gueguen S. Maturation signs of the cervix and prediction of preterm birth. Obstetrics and Gynecology 1986; 68:209-14.

8. Kirkpatrick LA, Feeney BC. A simple guide to IBM SPSS statistics for version 20.0. Student ed. Belmont, Calif.: Wadsworth, Cengage Learning; 2013.

9. Royal College of Obstetricians and Gynaecologists (RCOG), Induction of labour. In Evidence-base Clinical Guideline Number 9. London: RCOG Clinical Support Unit, 2001.
10. Verhoeven CJ, Opmeer BC, Oei SG, Latour V, vander Post JA, Mol BW. Transvaginal sonographic assessment of cervical length and wedging for predicting outcome of labor induction at term: A systematic review and meta-analysis. Ultrasound Obstet Gynecol 2013;42:500-8

11. El-Mekkawi SF, Hanafi S, Khalaf-Allah AE, Abdelazim IA, Awadalla AM, et al. Cervical Length Versus Modified Bishop's Score for Prediction of Successful Labor doi: 10.4103/2278960X.194488.

12. Kanwar SN, Reena P, Priya BK. A comparative study of trans vaginal sonography and modified Bishop score for cervical assessment before induction of labour. Sch J App Med Sci 2015;3:2284-8.

13..Panchampreet Kaur, Manpreet Kaur, Manjula Rao, Mini Mohan. Role of transvaginal sonography in preiduction cervical assessment. Is it helpful?. IJCMR 2017;4:1549-54.

14. Bastani P, Hamdi K, Abasalizadeh F, Pourmousa P, Ghatrehsamani F. Transvaginal ultrasonography compared with Bishop score for predicting cesarean section after induction of labor. Int J Womens Health 2011;3: 277.

15. Ezebialu IU, Eke AC, Eleje GU, Nwachukwu CE. Methods for assessing pre-induction cervical ripening. Cochrane Database Syst Rev 2015;(6):1-31.

16. Daskalakis G, Thomakos N, Hatziioannou L, Mesogitis S, Papantoniou N, Antasaklis A. Sonographic cervical length measurement before labour induction in term nulliparous women. J Fetal Diagn There 2006;21:34-8. 